dence, in point of time, of the former, or vice versa; but that either are dependent upon the other for their origin is a gratuitous and hypothetical statement.

The existence of an epidemic or epizootic atmosphere-if I may be permitted the use of such an expression-is equally operative in the production of this class of discases in both cases; in other words, the atmospheric influences which produce epidemics originate epizootics likewise.

In the second place, I would express my concurrence with the majority of the opinions recently advanced by Mr. Fleming in reference to variola, and would also call attention to some facts which have come under my notice at different times as to the prevalence, in England, of variola vaccina.

Some nine or ten years ago I saw cases of this disease in the neighbourhood of Blackburn, in which district it was well known. During the past eight years I have occasionally met with typical cases in the dairies of Edinburgh and Leith, and, with the exception of a few, all have passed through a regular course with but very slight apparent illness, or diminution of, or interference with, the lacteal secretion.

So little is the milk altered in its characters that it is a very rare occurrence for it to be kept separate from the daily yield. I have myself, on several occasions, examined such milk very carefully, microscopically, and otherwise, and in no instance have $I$ been able to detect any material departure from the normal condition.

If small-pox were dependent upon variola vaccina for its existence we should expect that it would be unusually prevalent in Edinburgh and Leith, particularly amongst the families of cow-feeders. I believe I am justified in saying that such is not the case.

All the cows which suffer from variola vaccina in this neighbourhood are brought from North Lancashire (collected usually at Preston from the surrounding districts), from Cumberland, and Westmoreland, hence it should be an easy matter for medical men residing in these counties to institute inquiries as to the relative prevalence of small-pux and variola vaccina.

The remark made in your issue of February 28th, by Dr. H. D'O. Foote, to the effect that the animals which he saw suffering from $V$. vaccina were sickly, thin, and miserable, is probably to be explained by the treatment to which they had been subjected. I have observed in my book on "The Four Bovine Scourges," that when cows are cared for during the febrile stage of eczema epizootica the suffering is comparatively slight, but if they had been subjected to exposure or hardships in travelling the fever is aggravated and the subsequent results very grave. The same remarks apply equally to $V$. vaccina. As to the measles of pigs, I have frequently observed rubeolous affections in these animals running through a course almost identical with that of measles in the human subject, and have looked upon such cases as in every sense analogous to that exanthem.

Canine variola is often met with here. Lastly, in reference to the remarks recently made by Charcot as to the prior existence or otherwise of a localised pneumonia in pulmonary tubercular disease, I may observe that whatever may be the case in the human subject, we seldom find traces of a previous pneumonia in the tuberculous lungs of cattle. I am, Sir, your obedient servant, THOMAS W ALLEY, Principal, Royal Dick's Veterinary College, Edinburgh.

\section{ANIMAL VACCINATION IN INDIA.}

To the Editor of THE LANCET.

SIR,-In the note on "Animal Vaccination in India," which appeared in your issue of the 24th of January last, you appear to share the fears of the Punjab Hindoo Association in regard to the loss of caste which a Hindoo would incur in consequence of being vaccinated from lymph taken from the teats or udder of a heifer or cow. Permit me to observe, that if this matter may be judged by the practical experience of Bombay, the most populous city in India, these fears are perfectly groundless. Compulsory vaccination, and chiefly animal vaccination, has been established here for the last three years; the lymph used is mostly that from the udder of the heifer. Not only has objection to this lymph not been taken by the Hindoos, but animal vaccination is preferred to arm-to-arm vaccination. The people are quite pleased, because their vaccinated children are not usually required to contribute the lymph for extend. ing the system. The Guzerathee portion of the Hindoo community of Bombay are quite as full of caste prejudices as any other Hindoos in British India, and yet they accept vaccination from the heifer as an unmixed blessing. The prejudices of the Punjab Hindoos appear to me to belong to Buddhism. When, several centuries ago, Brahminism regained the ascendancy in India and displaced Buddhism, some of the minor prejudices of the latter sect were neces. sarily transferred with the change; and this fear of heifer vaccination may be one of these prejudices. In Sanscrit literature the ordinary name for a guest is cow-killer; and no feast is said to be worthy of the name at which animal food was not provided.

Be this as it may, nothing has yet occurred to induce the Government of India to withhold a Compulsory Vaccination Act; nothing to prevent the free use of animal vaccination in any town or city in this country. Considering the vast benefits which a complete system of vaccination would con. fer upon India, it seems to me to be a matter of much regret that any educated public Hindoo body should engage itself in searching out fancied objections to animal vaccination at a time when the very life of the country requires that if any appeal is made to the people at all it should be an appeal to reason and common sense rather than to the spurions literature of an effete age. It is true in India that when. ever Government have passed a well-considered law, which even the ignorant ryot can perceive will benefit all classes of the people, all prejudice has been at once forgotten, and a loyal obedience has been at once rendered. This has oc. curred in Bombay with the Compulsory Vaccination Act, and it will occur everywhere else in the country if Government has the courage of its opinion.

Whether arm-to-arm vaccination is to be preferred to animal vaccination is not now the question. Bombay ex. perience is in favour of animal vaccination, especially amongst the poor with skins more or less diseased; but time is required before its protective influence can be accurately determined. If a Hindoo can be found weak. minded enough to object to animal vaccination, the remedy is at hand, and he may have his choice of human lymph, but such a man will have to meet a Hindoo vaccinator.

I trust, Sir, that the importance of this subject to the un. vaccinated hundreds of thousands of the people of India will secure for my remarks a place in your widely-circulated journal.

$$
\text { Bombay, Feb. 14th, 1880. Chairman Bombay Town Council. }
$$

\section{TRANSVERSE DEPRESSIONS ON THE NAILS.} To the Editor of THE LANCET.

SIR,-The point in Dr. Thin's communication of the 20th inst. is of some clinical and medico-legal importance. Several observers have recorded cases to illustrate the dates of ap. pearance and progress of these furrows. In particular, $\mathrm{Dr}_{1}$ Wilks and Dr. Langdon Down have contributed facts bear. ing on this subject. ${ }^{1}$ I have often observed the course of these depressions, and am inclined to agree with the recorded statements. I think, however, that there is a rather more rapid formation of nail than that of two complete growths in the year. Certainly, the rate of formation varies in different people, and at different seasons of the year. It is also in. fluenced by the habits and occupation of the individual. I am, Sir, your obedient servant,

Grafton-street, March 22nd. DYCE DUCKWORTH, M.D.

\section{THE RANK OF THE DIRECTOR-GENERAL OF THE ARMY MEDICAL DEPARTMENT.}

To the Editor of THE LANCET.

SIR, - While the Director-General has been fighting and winning battles for the benefit of his brother officers, he has forgotten to claim justice for himself. I allude now to the very inferior relative rank granted this officer. As you are aware, every surgeon-general of the Army Medical Depart. ment ranks with a major-general in the army-a fair and just rule ; but the Director-General of the whole department

1 Vide Mr. Hutchinson's Lectures on Clinical Surgery, 1878, p. 144. 